\title{
Sliding wear behavior of fully nanotwinned Cu alloys
}

\author{
Jianfeng YAN ${ }^{1,2}$, Andrew LINDO ${ }^{1}$, Ruth SCHWAIGER ${ }^{3}$, Andrea M. HODGE ${ }^{1, *}$ \\ ${ }^{I}$ Department of Aerospace and Mechanical Engineering, University of Southern California, Los Angeles, CA 90089, USA \\ ${ }^{2}$ Department of Mechanical Engineering, Tsinghua University, Beijing 100084, China \\ ${ }^{3}$ Institute for Applied Materials, Karlsruhe Institute of Technology (KIT), Eggenstein-Leopoldshafen 76344, Germany \\ Received: 01 October 2017 / Revised: 25 January 2018 / Accepted: 24 April 2018 \\ (C) The author(s) 2018. This article is published with open access at Springerlink.com
}

\begin{abstract}
Highly nanotwinned (NT) metals have advantages such as high strength, good ductility, favorable corrosion resistance, and thermal stability. It has been demonstrated that the introduction of high density NT microstructures can enhance the tribological properties of metals. However, the influence of the microstructure and the composition of NT alloys on the tribological behavior are not clear. In this work, the sliding wear behavior of fully NT materials, specifically $\mathrm{Cu}-\mathrm{Al}$ and $\mathrm{Cu}-\mathrm{Ni}$ alloys, are studied by a nanoscratch technique using a nanoindenter. The effects of microstructure and chemical composition on the wear properties are also studied. The results show that the chemical composition has an obvious influence on the wear resistance and microstructural deformation. For NT Cu-Al alloys, the hardness and sliding wear resistance improve with increased $\mathrm{Al}$ content from $\mathrm{Cu}-2 \mathrm{wt} . \% \mathrm{Al}$ to $\mathrm{Cu}-6 \mathrm{wt} . \% \mathrm{Al}$. NT $\mathrm{Cu}-10 w t . \% \mathrm{Ni}$ alloy shows even better wear resistance than $\mathrm{Cu}-6 \mathrm{wt}$.\%Al. The microstructural analysis shows that NT Cu alloys with higher wear resistance correspond to a smaller deformation-affected zone. The improvement of sliding wear properties of $\mathrm{Cu}-\mathrm{Al}$ alloys with higher Al content may be ascribed to their decreased stacking fault energy. NT Cu-Ni alloy shows better wear resistance than $\mathrm{Cu}-\mathrm{Al}$ alloy, this may be related to the formation of intermetallic compounds in $\mathrm{Cu}-\mathrm{Al}$ system. This study broadens the knowledge about tribological properties of NT materials and provides a potential method to optimize their sliding wear resistance by altering the chemical composition of NT Cu alloys.
\end{abstract}

Keywords: nanotwinned alloys; thin film; stacking fault energy; tribology

\section{Introduction}

Highly nanotwinned (NT) metals have shown potential as an alternative to nanocrystalline (NC) metals, as they exhibit excellent properties, such as high strength, good ductility, favorable corrosion resistance, and thermal stability [1-5]. These properties of NT metals provide an impetus for their development and mechanical characterization for structural applications $[6,7]$. However, in addition to the aforementioned properties, good tribological properties are also important for many engineering applications including both structural components and surface coatings [8].
The wear resistance of traditional engineering metals can often be simply related to hardness through the Archard equation, which states that the wear resistance is linearly proportional to the hardness [9]. It is also reported that hardness alone does not determine the wear resistance, as crack nucleation and propagation are also responsible for wear $[10,11]$. The wear properties of NC metals have attracted some attention, since NC metals generally have high hardness [12]. It is reported that both the hardness and wear resistance of $\mathrm{Ni}$ increases as the grain size decreases from microcrystalline to nanocrystalline scale [13]. However, when the grain size is smaller than $12 \mathrm{~nm}$,

* Corresponding author: Andrea M. HODGE; E-mail: ahodge@usc.edu 
Hall-Petch hardening seems to breakdown and the reduction of the grain size no longer improves the wear resistance [14]. For example, Luo et al. [15] reported cyclic sliding experiments of $\mathrm{Cu} / \mathrm{Au}$ multilayers and the formation of a microstructural vortex with increasing cycle number. For NT materials, the microstructural stability and hardness retention of multilayer $\mathrm{Cu} / \mathrm{Cu}$ with nanoscale twins under fatigue loading and indentation has been demonstrated $[16,17]$. Although the microstructural stability of NT materials is enhanced during cyclic deformation, the tribological properties of NT materials are still not well understood [16, 18, 19]. Zhang et al. [20] reported that the sliding wear properties of a $\mathrm{Cu}$ plate with a NT microstructural layer was better than those of equiaxed nanocrystalline $\mathrm{Cu}$ and coarse-grained $\mathrm{Cu}$ samples. Work by Singh et al. [8] confirmed that high-density NT Cu exhibited improved resistance to surface damage and to microstructural changes after an initial sliding pass; however, both low-density and high-density NT Cu exhibited similar surface hardness and microstructure after several sliding passes. These studies demonstrate that the introduction of high density NT microstructures can enhance the tribological properties of metals; however, details regarding the influence of the microstructure and the composition of materials have not yet been reported. To the best of our knowledge, no information is available in the literature concerning the tribological behavior of NT alloys.

In the present paper, the sliding wear behavior of fully NT materials, specifically $\mathrm{Cu}-\mathrm{Al}$ and $\mathrm{Cu}-\mathrm{Ni}$ alloys, is studied using a nanoindenter, which is a convenient method to assess the wear properties of materials [21]. The microstructural deformation under the tracks was examined. The effect of chemical composition on the wear properties and microstructural deformation of these materials will be discussed in this paper.

\section{Experimental details}

Fully NT columnar films of Cu-2wt.\%Al, Cu-4wt.\%Al, $\mathrm{Cu}-6 w t . \% \mathrm{Al}$, and $\mathrm{Cu}-10 \mathrm{wt}$.\%Ni were synthesized by magnetron sputtering; detailed information on these materials has been published in the literature [22]. The microstructural characterization of the as-deposited films was conducted using scanning electron microscopy (SEM, JEOL JSM-7001) of focused-ion-beam prepared cross sections (SEM/FIB, NanoLab200, FEI Company, Hillsboro, OR, USA) and transmission electron microscopy (TEM, JEOL JEM-2100F). Crosssectional TEM samples were generated by mounting a cross section of the film on silicon, then dimple grinding and ion milling using a Fischione Model 1050 TEM Mill. The grain width and twin thickness were determined from TEM images using bright field, dark field, and high-resolution images.

The nanoindentation and wear testing of the metals was performed on a Nanoindenter XP (MTS, MN, USA) equipped with a piezo-driven nanopositioning stage. The hardness and elastic modulus measurements were conducted using a Berkovich tip in sets of 20 indents, where all indents were $2 \mu \mathrm{m}$ deep and $50 \mu \mathrm{m}$ apart from the next. Reciprocating wear tests were conducted with a spherical diamond tip of $10 \mu \mathrm{m}$ tip radius and $60^{\circ}$ cone angle. The specimens were glued onto steel specimen holders using cyanoacrylate glue for the frictional sliding experiments. Scratch tests with a constant applied load of $5 \mathrm{mN}$ were conducted at a speed of $10 \mu \mathrm{m} / \mathrm{s}$ over a length of $100 \mu \mathrm{m}$ by moving the nanopositioning stage back and forth. The tip was cleaned after every experiment in order to avoid wear debris transfer between experiments. The depth and width of the wear tracks were obtained using SEM and surface profilometry (Ambios XP2 profilometer). Microstructure characterization after the scratch tests was performed using SEM and FIB microscopy to assess deformation-induced microstructural changes.

\section{Results and discussion}

Figure 1(a) presents a typical FIB cross-sectional image of the microstructure of an as-sputtered $\mathrm{Cu}-2 \mathrm{wt} . \% \mathrm{Al}$ alloy. Figures 1(b) and 1(c) show cross-sectional TEM images of $\mathrm{Cu}-\mathrm{Al}$ alloys indicating the grain width and the twin thickness. The sample has a typical columnar grain structure, with twins within the columnar grains. The presence of NTs is confirmed by a selected-area electron diffraction (SAED) pattern shown in Fig. 1(b). The SAED pattern shows the typical double hexagon pattern of (110) zone axis oriented twinned grains. 

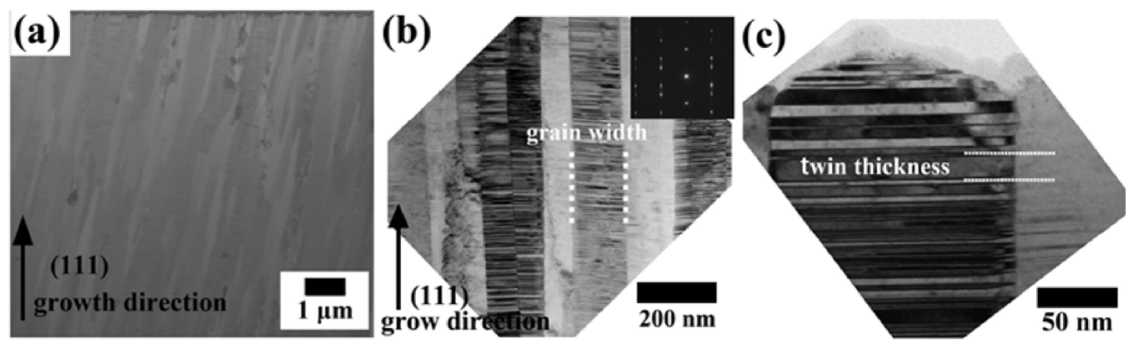

Fig. 1 (a) Representative FIB cross-sectional image and (b and c) cross-sectional TEM images of a NT Cu-2wt.\%Al alloy. Inset is selected area electron diffraction (SAED) pattern.

Table 1 summarizes the measured grain widths and twin thicknesses (volume weighted average) as well as the hardness, modulus and friction coefficient for the tested NT alloy samples. It is known that the hardness of materials is one of the most important mechanical properties related to tribological properties $[8,23]$. For NT Cu-Al alloys, the hardness increases as the $\mathrm{Al}$ content increases from $2 \mathrm{wt} . \%$ to $6 \mathrm{wt} . \%$. This is consistent with tensile test results of NT Cu-Al alloys, which show an increased tensile strength with higher $\mathrm{Al}$ content [24]. The modulus of $\mathrm{Cu}$ alloy is higher than that of pure copper. A major contribution to this increased modulus arises from $\mathrm{Al}$ in solid solution. It is also shown that $\mathrm{Cu}-\mathrm{Ni}$ alloys have a higher elastic modulus that is accompanied by a higher hardness compared with $\mathrm{Cu}-\mathrm{Al}$ alloys.

While the friction coefficient for the different samples was obtained over the whole scratch length using the nanoindenter, we reported the values averaged over the sliding distance between $30-70 \mu \mathrm{m}$ to account for the deceleration and acceleration of the stage at the ends of the tracks. The friction coefficient represents the friction between the NT alloys and the diamond nanoindenter tip [10]. Figure 2(a) illustrates the change of the friction coefficient as a function of cycle number with one cycle describing one back-and-forth pass. A "steady-state" value is reached after approximately 40 back-and-forth passes in all four materials. The friction coefficient and wear resistance values shown in Table 1 are for 50 sliding cycles $(N=50)$.

The wear deformation during a sliding test can be assessed by the dimensionless wear coefficient [25], $k$, or wear resistance, $R_{w}$. Here, $k$ is calculated according to the classical equation [9]:

$$
k=V H / P x
$$

where $V$ is the total amount of displaced material, which is calculated based on the depth and width of the track (shown in Table1), $H$ is the hardness of the material (shown in Table 1), $x$ is the total distance of travel $(100 \mu \mathrm{m} \times 100)$, and $P$ is the applied load $(5 \mathrm{mN})$. Moreover, $R_{w}$ is obtained by the following equation [26]:

$$
R_{w}=H / k
$$

The calculated wear resistances of NT alloys are listed in Table 1. For NT Cu-Al alloys, the Cu-6wt.\%Al is the most wear resistant alloy, followed by $\mathrm{Cu}-4 \mathrm{wt} . \% \mathrm{Al}$ and $\mathrm{Cu}-2 \mathrm{wt} . \% \mathrm{Al}$. It should be noted that the wear resistance of the NT Cu-4wt.\%Al alloy is lower than that of the NT Cu-6wt.\%Al alloy, despite its smaller grain width and twin thickness. While it has been

Table 1 Summary of sliding tests results for $\mathrm{Cu}$ alloys with microstructure and composition.

\begin{tabular}{cccccccccc}
\hline Material & $\begin{array}{c}\mathrm{SFE}^{*} \\
\left(\mathrm{~mJ} / \mathrm{m}^{2}\right)\end{array}$ & $\begin{array}{c}\text { Grain } \\
\text { width } \\
(\mathrm{nm})\end{array}$ & $\begin{array}{c}\text { Average twin } \\
\text { thickness } \\
(\mathrm{nm})\end{array}$ & $\begin{array}{c}\text { Elastic } \\
\text { modulus } \\
(\mathrm{GPa})\end{array}$ & $\begin{array}{c}\text { Hardness } \\
(\mathrm{GPa})\end{array}$ & $\begin{array}{c}\text { Friction } \\
\text { coefficient } \\
(\mu)(N=50)\end{array}$ & $\begin{array}{c}\text { Volume } \\
\text { removed } \\
\left(\mathrm{m}^{3}\right)(N=50)\end{array}$ & $\begin{array}{c}\text { Wear } \\
\text { coefficient, } \\
K\end{array}$ & $\begin{array}{c}\text { Wear } \\
\text { resistance, } \\
R_{w}(\mathrm{~Pa})\end{array}$ \\
\hline $\mathrm{Cu}-2 w t . \% \mathrm{Al}$ & $37^{27}$ & $219 \pm 7$ & $10 \pm 1$ & $150 \pm 50$ & $3.1 \pm 0.6$ & 0.73 & $3.5 \times 10^{-18}$ & $2.91 \times 10^{-3}$ & $1.20 \times 10^{10}$ \\
$\mathrm{Cu}-4 w t . \% \mathrm{Al}$ & $13^{28}$ & $111 \pm 1$ & $5 \pm 1$ & $145 \pm 4$ & $3.5 \pm 0.1$ & 0.15 & $3.5 \times 10^{-18}$ & $1.93 \times 10^{-3}$ & $1.81 \times 10^{10}$ \\
$\mathrm{Cu}-6 w t . \% \mathrm{Al}$ & $6^{28}$ & $156 \pm 7$ & $13 \pm 1$ & $150 \pm 20$ & $3.8 \pm 0.4$ & 0.12 & $3.8 \times 10^{-18}$ & $1.52 \times 10^{-3}$ & $2.50 \times 10^{10}$ \\
$\mathrm{Cu}-10 w t . \% \mathrm{Ni}$ & $47-74^{31}$ & $226 \pm 7$ & $20 \pm 1$ & $180 \pm 20$ & $3.8 \pm 0.4$ & 0.15 & $3.8 \times 10^{-18}$ & $0.93 \times 10^{-3}$ & $4.07 \times 10^{10}$ \\
\hline
\end{tabular}

* The SFE were obtained from previous reports $[27,28,31]$. 

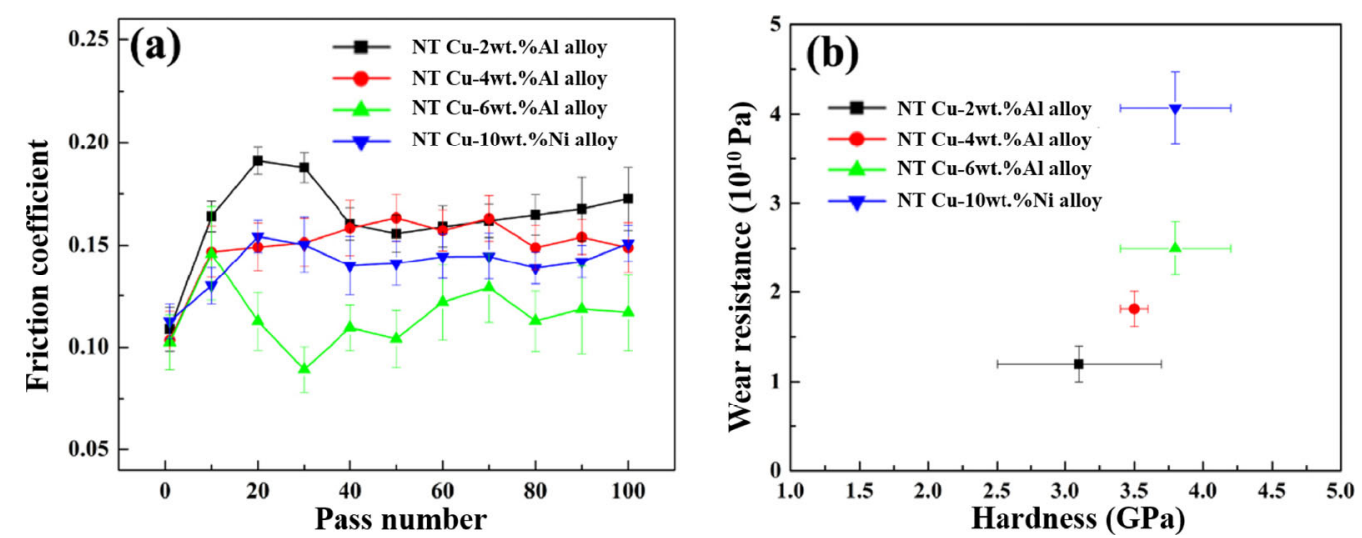

Fig. 2 (a) Friction coefficient as a function of sliding pass number for different NT Cu alloys and (b) comparison of wear resistance and hardness for NT Cu alloys.

reported that tribological properties are enhanced by decreasing the grain size in $\mathrm{Cu}[13,20]$, our results show that the wear resistance of $\mathrm{Cu}$ alloys is more dependent on the change of the chemical composition than on the microstructure. The sliding tests also demonstrated that the NT Cu-10wt.\%Ni alloy is the most wear resistant alloy of the samples tested. The correlation between wear resistance and hardness is illustrated in Fig. 2(b), which compares the relative material performance. It can be seen that hardness is an important factor in assessing the wear resistance of NT alloys, since a higher hardness usually correlates with a better wear resistance. However, it seems that the wear resistance of these NT Cu alloys does not exactly follow the classical Archard equation, which predicts wear resistance to be linearly proportional to hardness [10]. This might be related to changes in the microstructure, since the hardness was determined on the as-deposited films, while the wear resistance was evaluated after 50 sliding cycles. Work by Hodge et al. [10] also shows that the wear resistance of amorphous alloys also do not follow the classical Archard equation, i.e. the wear resistance is not linearly proportional to the hardness. In that work, the discrepancy was suggested to be a result of different wear mechanisms operating in different materials [10].

The different wear behaviors of NT alloys can also be examined by studying the wear morphologies of the different materials after scratch tests. The microstructure for specimens after 50 cycles was investigated using SEM and FIB. Figure 3 shows top-down SEM views of wear tracks with the sliding direction denoted by the arrow. In these images, surface plowing by asperities and a cracked transfer layer can be seen. The Cu-6wt.\%Al alloy exhibits a narrower sliding track than the $\mathrm{Cu}-4 \mathrm{wt} . \% \mathrm{Al}$ alloy, followed by the $\mathrm{Cu}-2 \mathrm{wt}$.\%Al alloy. A narrower sliding track and less surface damage were also observed in the $\mathrm{Cu}-10 \mathrm{wt}$.\%Ni alloy. The surface damage observed by SEM is consistent with the wear resistance results. To further investigate the wear behavior, Fig. 4 presents the cross-sectional images perpendicular to the sliding direction after 50 cycles. Structural changes under the sliding track can be observed for all samples. While the material in the vicinity of the surface shows significant detwinning and an equiaxed grain structure, it is surrounded by the original microstructure. The areas of the deformation-affected zone (Fig. 4) for different $\mathrm{Cu}$ alloys were calculated using Image J software (Rasband, WS, US National Institutes of Health, Bethesda, Maryland, USA). The calculated areas of the deformation-affected zones below the sliding tracks for Cu-2wt.\%Al, Cu-4wt.\%Al, Cu-6wt.\%Al, and $\mathrm{Cu}-10 \mathrm{wt} . \% \mathrm{Ni}$ are $1.06 \mu \mathrm{m}^{2}, 0.88 \mu \mathrm{m}^{2}, 0.62 \mu \mathrm{m}^{2}$, and $0.39 \mu^{2}$, respectively. It can be seen that $\mathrm{Cu}-10 w t . \% \mathrm{Ni}$ has the smallest deformation-affected zone. For $\mathrm{Cu}-\mathrm{Al}$ alloys, the size of the area decreases with higher $\mathrm{Al}$ content. It was shown that NT $\mathrm{Cu}$ alloys with higher wear resistance have a smaller deformation-affected zone, which suggests better microstructural stability. In other words, the wear resistance of NT $\mathrm{Cu}-\mathrm{Al}$ alloys is more dependent on the microstructure evolution than on the initial microstructure. A similar result has been observed in 


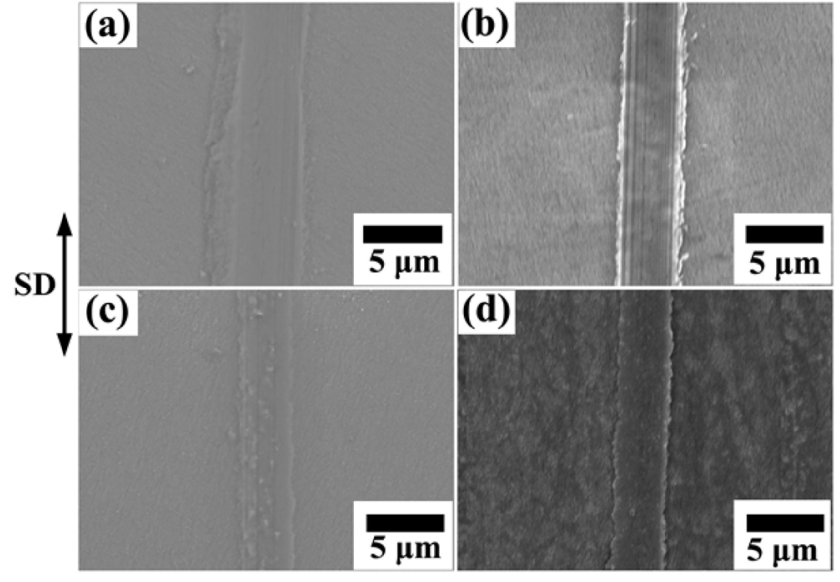

Fig. 3 Top view SEM micrographs of typical surface damage morphology in different NT $\mathrm{Cu}$ alloys after 100 sliding circles: (a) $\mathrm{Cu}-2$ wt.\%Al alloy; (b) $\mathrm{Cu}-4 w t . \% \mathrm{Al}$ alloy; (c) $\mathrm{Cu}-6 w t . \% \mathrm{Al}$ alloy; (d) $\mathrm{Cu}-10 \mathrm{wt} . \% \mathrm{Ni}$ alloy. Double pointed arrow indicates the sliding direction (SD) for all samples.
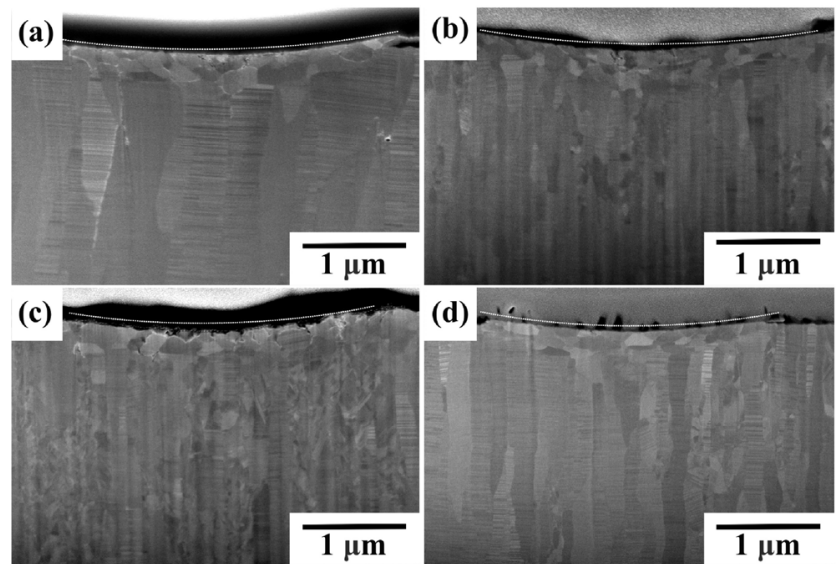

Fig. 4 FIB cross-sectional images (imaged at $52^{\circ}$ tilt angle) perpendicular to the sliding direction of NT $\mathrm{Cu}$ alloys showing deformation-induced microstructure changes in the vicinity of the scratch surface after 50 sliding passes. (a) Cu-2wt.\%Al alloy; (b) $\mathrm{Cu}-4 w t . \% \mathrm{Al}$ alloy; (c) Cu-6wt.\%Al alloy; (d) $\mathrm{Cu}-10 \mathrm{wt} . \% \mathrm{Ni}$ alloy. The position of the spherical indenter is indicated by the dashed line. In all cases, a clear boundary between the original microstructure and the deformed region can be observed.

repeated frictional sliding tests for $\mathrm{NT} \mathrm{Cu}$, in which it was found that friction evolution as well as the local mechanical response are more strongly influenced by a local structural evolution during repeated sliding than by the initial structure [8].

This study has shown that the wear resistance of $\mathrm{Cu}-\mathrm{Al}$ alloys increases with higher $\mathrm{Al}$ content and is accompanied by a smaller volume of changed microstructure. In addition to the improved hardness, the enhanced wear properties and microstructural stability of $\mathrm{Cu}-\mathrm{Al}$ alloys might be related to the difference of stacking fault energy (SFE). The SFE for NT Cu-Al alloys decreases with higher $\mathrm{Al}$ content as listed in Table 1 (Cu-2wt.\%Al $37 \mathrm{~mJ} / \mathrm{m}^{2}$ [27]; Cu4wt.\%Al $13 \mathrm{~mJ} / \mathrm{m}^{2}$ [28]; Cu-6wt.\%Al $6 \mathrm{~mJ} / \mathrm{m}^{2}$ [28]). Generally, the lower the value of the SFE, the harder it is for cross-slip to occur [29]. Lowering the SFE can reduce the mobility of dislocations by restricting the cross-slip, leading to the dislocation process associated with grain boundary migration being highly restrained [30, 31]. Furthermore, the introduction of $\mathrm{Al}$ atoms may pin the potential moving planes, thereby decreasing the grain boundary energy and dislocation velocity, and then drag or suppress the grain boundary motion [30, 32]. For these reasons, the $\mathrm{Cu}-\mathrm{Al}$ alloys with higher $\mathrm{Al}$ content might exhibit a smaller deformationaffected zone and increased wear resistance. Thus, the evolution of the microstructure under sliding contact is related to the SFE. However, it should be noted that the hardness and wear resistance of Cu-10wt.\%Ni (SFE 47-74 mJ/m²) [31] are both higher than those of the $\mathrm{Cu}-\mathrm{Al}$ alloys. This significant difference in wear resistance compared to the $\mathrm{Cu}-\mathrm{Al}$ NT alloys, despite the high SFE of Cu-10wt.\%Ni, may be related to the formation of intermetallic compounds in the $\mathrm{Cu}-\mathrm{Al}$ system [33] during sliding. This requires further study.

\section{Conclusions}

Four fully NT Cu alloys, Cu-2wt.\%Al, Cu-4wt.\%Al, Cu-6wt.\%Al, and $\mathrm{Cu}-10 \mathrm{wt} . \% \mathrm{Ni}$ were tested using a nanoindenter to acquire hardness, elastic modulus, and sliding wear properties. The elastic modulus of $\mathrm{Cu}-\mathrm{Al}$ alloys is about $150 \mathrm{GPa}$ and the modulus of $\mathrm{Cu}-10 w t . \% \mathrm{Ni}$ is $180 \mathrm{GPa}$. The hardness of $\mathrm{Cu}-\mathrm{Al}$ alloys increases with the $\mathrm{Al}$ content. The hardness of $\mathrm{Cu}-10 w t . \% \mathrm{Ni}$ is the same as $\mathrm{Cu}-6 \mathrm{wt} . \% \mathrm{Al}$, which is $3.8 \mathrm{GPa}$. Their wear resistance, in an ascending order, is $\mathrm{Cu}-2 \mathrm{wt} . \% \mathrm{Al}, \mathrm{Cu}-4 \mathrm{wt} . \% \mathrm{Al}, \mathrm{Cu}-6 \mathrm{wt} . \% \mathrm{Al}$, and $\mathrm{Cu}-10 w t . \% \mathrm{Ni}$. This suggests that the wear response of fully NT Cu alloys is mainly dependent on chemical composition. Microstructural analysis after the sliding wear tests showed that NT Cu alloys with higher wear resistance correspond to a smaller area of the 
deformation-affected zone under the indentation surface. The enhanced wear properties and microstructural stability of $\mathrm{Cu}-\mathrm{Al}$ alloys may be ascribed to the decrease of the SFE. Overall, NT Cu-Ni showed the best tribological properties, thus further highlighting the effect of composition. This investigation suggests that the chemical composition has a larger effect on the wear behavior than initial microstructure, including grain width and twin thickness, at least for the following fully NT Cu alloys: Cu-2wt.\%Al, Cu-4wt.\%Al, Cu-6wt.\%Al, and Cu-10wt.\%Ni.

\section{Acknowledgements}

This work was performed under the auspices of the National Science Foundation (Grant Nos. NSF-DMR0955338 and NSF-OISE-1460006). The authors would like to thank Leonardo Velasco for preparing the sputtered samples, Nathan Heckman for his discussions, and are grateful to the Center for Electron Microscope and Microanalysis (CEMMA) for the characterization facilities.

Open Access: The articles published in this journal are distributed under the terms of the Creative Commons Attribution 4.0 International License (http://creativecommons.org/licenses/by/4.0/), which permits unrestricted use, distribution, and reproduction in any medium, provided you give appropriate credit to the original author(s) and the source, provide a link to the Creative Commons license, and indicate if changes were made.

\section{References}

[1] Lu K, Lu L, Suresh S. Strengthening materials by engineering coherent internal boundaries at the nanoscale. Science 324(5926): 349-352 (2009)

[2] Lu L, Shen Y F, Chen X H, Qian L H, Lu K. Ultrahigh strength and high electrical conductivity in copper. Science 304(5669): 422-426 (2004)

[3] Zhao Y, Cheng I C, Kassner M E, Hodge A M. The effect of nanotwins on the corrosion behavior of copper. Acta Mater 67: 181-188 (2014)

[4] Zhao Y F, Furnish T A, Kassner M E, Hodge A M. Thermal stability of highly nanotwinned copper: The role of grain boundaries and texture. J Mater Res 27(24): 3049-3057 (2012)

[5] Yan J F, Heckman N M, Velasco L, Hodge A M. Improve sensitization and corrosion resistance of an $\mathrm{Al}-\mathrm{Mg}$ alloy by optimization of grain boundaries. Sci Rep 6: 26870 (2016)

[6] Li X Y, Wei Y J, Lu L, Lu K, Gao H J. Dislocation nucleation governed softening and maximum strength in nano-twinned metals. Nature 464(7290): 877-880 (2010)

[7] Li X Y, Dao M, Eberl C, Hodge A M, Gao H J. Fracture, fatigue, and creep of nanotwinned metals. MRS Bull 41(4): 298-304 (2016)

[8] Singh A, Dao M, Lu L, Suresh S. Deformation, structural changes and damage evolution in nanotwinned copper under repeated frictional contact sliding. Acta Mater 59(19): 7311-7324 (2011)

[9] Archard J F. Contact and rubbing of flat surfaces. J Appl Phys 24(8): 981-988 (1953)

[10] Hodge A M, Nieh T G. Evaluating abrasive wear of amorphous alloys using nanoscratch technique. Intermetallics 12(7-9): 741-748 (2004)

[11] Wong C J, Li J C M. Wear behavior of an amorphous alloy. Wear 98: 45-61 (1984)

[12] Farhat Z N, Ding Y, Northwood D O, Alpas A T. Effect of grain size on friction and wear of nanocrystalline aluminum. Mater Sci Eng A 206(2): 302-313 (1996)

[13] Jeong D H, Gonzalez F, Palumbo G, Aust K T, Erb U. The effect of grain size on the wear properties of electrodeposited nanocrystalline nickel coatings. Scripta Mater 44(3): 493-499 (2001)

[14] Schuh C A, Nieh T G, Yamasaki T. Hall-Petch breakdown manifested in abrasive wear resistance of nanocrystalline nickel. Scripta Mater 46(10): 735-740 (2002)

[15] Luo Z P, Zhang G P, Schwaiger R. Microstructural vortex formation during cyclic sliding of $\mathrm{Cu} / \mathrm{Au}$ multilayers. Scripta Mater 107: 67-70 (2015)

[16] Shute C J, Myers B D, Xie S, Barbee T W Jr, Hodge A M, Weertman J R. Microstructural stability during cyclic loading of multilayer copper/copper samples with nanoscale twinning. Scripta Mater 60(12): 1073-1077 (2009)

[17] Shute C J, Myers B D, Xie S, Li S Y, Barbee T W, Hodge A M, Weertman J R. Detwinning, damage and crack initiation during cyclic loading of $\mathrm{Cu}$ samples containing aligned nanotwins. Acta Mater 59(11): 4569-4577 (2011)

[18] Singh A, Tao N R, Dao M, Suresh S. Repeated frictional sliding properties of copper containing nanoscale twins. Scripta Mater 66(1): 849-853 (2012)

[19] Hodge A M, Furnish T A, Shute C J, Liao Y, Huang X, Hong C S, Zhu Y T, Barbee T W Jr, Weertman J R. Twin stability in highly nanotwinned $\mathrm{Cu}$ under compression, torsion and tension. Scripta Mater 66(11): 872-877 (2012)

[20] Zhang Y S, Wang K, Han Z, Liu G. Dry sliding wear behavior of copper with nano-scaled twins. Wear 262(11-12): 1463-1470 (2007) 
[21] Li X D, Bhushan B. A review of nanoindentation continuous stiffness measurement technique and its applications. Mater Charact 48(1): 11-36 (2002)

[22] Velasco L, Hodge A M. The mobility of growth twins synthesized by sputtering: Tailoring the twin thickness. Acta Mater 109: 142-150 (2016)

[23] Rigney D A. The roles of hardness in the sliding behavior of materials. Wear 175(1-2): 63-69 (1994)

[24] Heckman N M, Velasco L, Hodge A M. Influence of twin thickness and grain size on the tensile behavior of fully nanotwinned CuAl alloys. Adv Eng Mater 18(16): 918-922 (2016).

[25] Hutchings I M, Shipway P. Tribology: Friction and Wear of Engineering Materials. Boca Raton: CRC Press, 1992.

[26] Rabinowicz E, Dunn L A, Russell P G. A study of abrasive wear under three-body conditions. Wear 4(5): 345-355 (1961)

[27] Grace F I, Inman M C. Influence of stacking fault energy on dislocation configurations in shock-deformed metals. Metallography 3(1): 89-98 (1970)

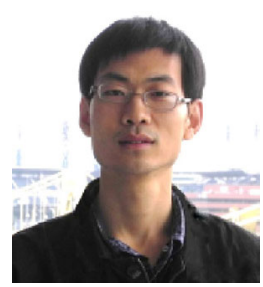

Jianfeng YAN. He received his Ph.D. degree in materials science from Tsinghua University, China in 2013. After then he has worked as post-doctoral research associate at

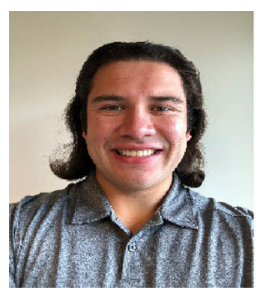

Andrew LINDO. He received his B.S. degree in aerospace engineering from University of Southern California in 2017, where he was an

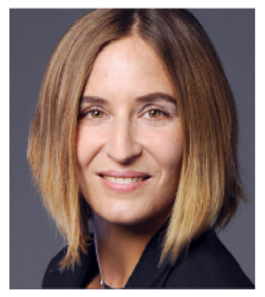

Ruth SCHWAIGER. She is head of the nanomechanics research group at the Karlsruhe Institute of Technology (KIT). She conducted her doctoral research at the MaxPlanck-Institute for Metals Research in Stuttgart, Germany, and obtained her doctoral degree in materials science from the University of Stuttgart in 2002. After her postdoctoral research at the Massachusetts Institute of Technology, she joined
[28] Rohatgi A, Vecchio K S, Gray III G T. The influence of stacking fault energy on the mechanical behavior of $\mathrm{Cu}$ and $\mathrm{Cu}-\mathrm{Al}$ alloys: Deformation twinning, work hardening, and dynamic recovery. Metall Mater Trans A 32(1): 135-145 (2001)

[29] Meyers M A, Chawla K K. Mechanical Behavior of Materials. 2nd ed. Cambridge: Cambridge University Press, 2009.

[30] Schäfer J, Albe K. Influence of solutes on the competition between mesoscopic grain boundary sliding and coupled grain boundary motion. Scripta Mater 66(5): 315-317 (2012)

[31] Li W, Lu S, Hu Q M, Kwon S K, Johansson B, Vitos L. Generalized stacking fault energies of alloys. $J$ Phys: Condens Matter 26(26): 265005 (2014)

[32] An X H, Wu S D, Wang Z G, Zhang Z F. Enhanced cyclic deformation responses of ultrafine-grained $\mathrm{Cu}$ and nanocrystalline $\mathrm{Cu}-\mathrm{Al}$ alloys. Acta Mater 74: 200-214 (2014)

[33] Massalski T B, Okamoto H, Subramanian P R, Kacprzak L. Binary Alloy Phase Diagrams. 2nd ed. Materials Park, $\mathrm{OH}$ : ASM International, 1990.

Viterbi School of Engineering, University of Southern California, USA. In 2017, he joined Tsinghua University as an assistant professor of mechanical engineering. His research interests include nanocrystalline materials processing.

undergraduate assistant in the Hodge materials nanotechnology research group for 4 years. His research interests include nanoindentation and wear on bulk materials and multilayered films.

the Forschungszentrum Karlsruhe in Germany in 2004 and then moved to a management consulting firm in 2007. She joined KIT in 2010. Her research interests range from deformation mechanisms in metals and the mechanics of small-scale materials and structures to biomechanics and mechanical metamaterials. Her research aims to develop a mechanism-based understanding of deformation and failure of materials, and to determine design principles impacting improved strength and damage tolerance. 


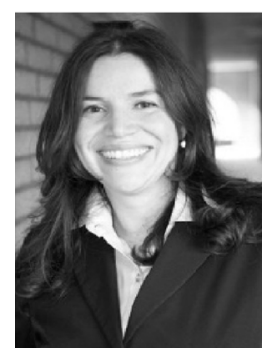

Andrea M. HODGE. She is the Arthur B. Freeman professor of chemical engineering and materials science, and of aerospace and mechanical engineering. She received her Ph.D. degree in materials science from Northwestern University, in
2002, and became a postdoctoral fellow at Lawrence Livermore National Laboratory that same year. In 2007, she joined USC as an assistant professor of aerospace and mechanical engineering. Her research interests range from processing of nanocrystalline and nanoporous materials to nanomechanics of multilayers and thin films. 